\title{
PRODUÇÃO E AVALIAÇÃO DAS PROPRIEDADES FÍSICAS E MECÂNICAS DE "MADEIRA SINTÉTICA" PROCESSADA A PARTIR DO RESÍDUO DO BENEFICIAMENTO DO AÇAI.
}

\author{
R. O. GOES ${ }^{1}$, S. O. MORENO ${ }^{2}$ e F. F. C. TAVARES ${ }^{3}$ \\ ${ }^{1}$ Universidade do Estado do Amapá, Colegiado de Engenharia Química \\ ${ }^{2}$ Universidade do Estado do Amapá, Colegiado de Engenharia \\ ${ }^{3}$ Universidade do Estado do Amapá, Colegiado de Engenharia Química \\ E-mail para contato: robson.goes.ap@gmail.com
}

\begin{abstract}
RESUMO - O açaí é uma fruta encontrada em abundancia no estado do Amapá, seu consumo produz uma grande produção de resíduos sólidos que são despejados no meio ambiente de forma inadequada e que pode ser considerada uma forma de poluição.Este trabalho oferece uma aplicação a um resíduo vegetal, o caroço de açaí, mais precisamente a fibra. Com ele propõe-se a produção de um compósito de matriz polimérica resinosa sintética reforçada com fibras vegetais, a fibra do açaí, produzindo-se um compósito que substituirá a madeira natural.O trabalho fornecerá um novo material para o setor econômico do Estado, uma madeira sintética, (que vai desafogar a quantidade de resíduos vegetais de caroços estocados ou usados em tecnologia pobres como na alimentação energética de fornos cerâmicos), além de diminuir a necessidade da exploração irregular de algumas espécies vegetais, disponibilizando um novo material a ser usado na construção civil e arquitetura, no setor moveleiro, no design, e por fim agregar valores a um produto pouco apreciado e rejeitado, o caroço de açaí.A maioria dos compósitos reforçados com fibras apresentam propriedades mecânicas avantajadas como maior limite de resistência, com a realização do ensaio de flexão de acordo com a Norma NBR 14810, 2002 observou-se uma boa resistência do material.
\end{abstract}

\section{INTRODUÇÃO}

No passado a reciclagem de materiais surgiu da necessidade ambiental,mas nem tanto tecnológica de se diminuir a carga de resíduos depositados em aterros, lixões ou em qualquer outro lugar inadequado a sua locação.

Atualmente a reciclagem passa por uma nova reflexão tecnológica,mostrando que com a falta de novas matérias primas, o resíduo deve ser reaproveitado ou transformado a fim de suprir as necessidades de determinados processos. Desta forma o desenvolvimento de materiais reciclados com características tecnológicas dentro dos padrões de qualidade é a meta da engenharia do presente. 


\section{9 a 22 de outubro de 2014 \\ Florianópolis/SC}

Baseado na linha de tendência atual de produzir compósitos de matriz polimérica reforçada por fibras vegetais (observado por algumas referencias citadas na revisão da literatura que segue adiante)acreditamos que o uso destas processadas a partir do caroço do açaí, possam render materiais compósitos tecnologicamente aplicáveis nas diversas indústria que já são aplicados materiais madeireiros.

Compósitos de matriz polimérica reforçados por fibras

A fibra é um material que possui resistência à ruptura, e, consequentemente, módula de elasticidade muito maior que o próprio material não transformado em fibra. Por exemplo, a fibra de vidro pode ter resistência à ruptura 500 vezes maior que um bloco de vidro, isso é possível por conta da eliminação dos defeitos de superfície que o material possuía como bloco (MARINHO, 2005).

A. A fase fibra.

A maioria dos compósitos reforçados com fibras apresentam propriedades mecânicas avantajadas como maior limite de resistência; resistência à fadiga;módulo de Young e resistência específica ao incorporar fibras mecanicamente resistentes, mas frágeis em uma matriz com menor massa específica e mais dúctil (ASKELAND e PHULÉ, 2008).

\section{A.1. Fibras vegetais.}

As fibras vegetais vêm sendo estudadas ao longo de décadas, no que se referem a sua constituição, propriedades mecânicas e seus possíveis usos, Sabarizet al, (2006).

A incorporação de fibras vegetais no reforço de polímeros vem se tornando muito frequente devido à necessidade de buscar soluções tecnológicas para a redução do volume de resíduos gerados e uma melhor forma de reaproveitá-los para a produção de um produto que possa substituir o uso de produtos naturais.

B. A fase matriz.

A fase matriz dos compósitos fibrosos pode ser constituída por um metal,polímero ou cerâmica. Os metais e polímeros são mais frequentemente utilizados como materiais de matrizes, pois, geralmente alguma ductilidade é desejada no compósito, já para os compósitos com matriz cerâmica o componente de reforço é adicionado com o intuito de melhorar a tenacidade à fratura.

Segundo Callister (2008), os compósitos que possuem reforço de fibras na matriz, são multifuncionais. Primeiramente ela une as fibras umas às outras e atua como meio de transmissão da tensão aplicada entre as fibras, resultando que apenas uma parcela pequena de uma carga aplicada é suportada pela matriz. Outra função é proteger as fibras individuais contra os danos superficiais causados por meio de abrasão mecânica ou de reações químicas com o ambiente. Tais interações produzem defeitos superficiais que podem formar trincas, as quais aumentam as chances de ocorrer falha quando submetidas a baixos níveis de tensão de tração. 
Por fim, a matriz separa as fibras, e, possuindo baixa dureza e plasticidade, previne a propagação de trincas frágeis de uma fibra para outra, o que poderia ressaltar em uma falha catastrófica, resumindo, a matriz é como uma barreira contra a propagação de trincas.

Segundo o mesmo autor, um importante fator na seleção de uma combinação matriz-fibra, é a resistência da ligação. A resistência máxima do compósito depende em grande parte da magnitude dessa ligação, uma ligação adequada é essencial para maximizar a transmissão de tensão de uma matriz de baixa resistência para uma fibra mais resistente.

C. O açaí como matéria prima para a produção de compósito.

O caroço do açaí na figura 01 é rico em celulose $(53,20 \%)$, hemicelulose $(12,26 \%)$ e lignina (22,30\%) (RODRÍGUEZ 2008).

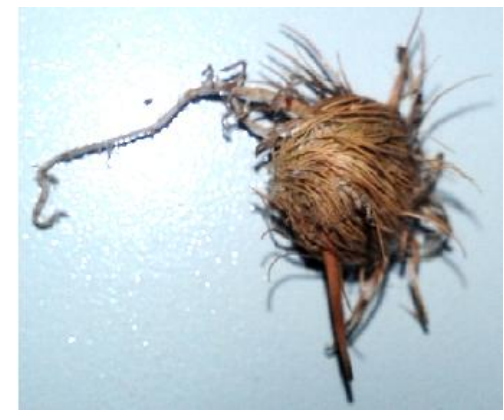

Figura 01 - Caroço do açaí

A região norte é responsável por grande parte da produção nacional do fruto açaí, tendo como principal produtor o Estado do Pará com 87,4\% da produção nacional (IBGE - 2006). O Estado do Amapá embora produza menos, tem participação de 1,2\% da produção, totalizando 1337 toneladas do fruto, destas, 15\%(200,6 ton.), apenas são aproveitados como produto de consumo pela população,produto este o "vinho de açaí", os outros 85\% (1136,4 ton.) são resíduos (caroço e fibra), formados por esta atividade produtiva (IBGE - 2009; SAGRI/PA - 2011).

Para o resíduo já existem diversas aplicações tecnológicas, por exemplo:como fonte de biomassa para combustão em olarias; suas fibras são usadas para produção de estofados e xaxins; o caroço é usado por designes para fabricação de biojoias, entre outras. Destas, a maior aplicação no Amapá é a primeira, que por sua vez, acaba gerando poluentes para a atmosfera. 


\section{MATERIAIS E MÉTODOS}

Preparo da fibra de açaí.

Os caroços de açaí foram coletados em batedoras de açaí espalhadas nos bairros da cidade de Macapá. Após a coleta, lavou-se os caroços com água utilizando-se uma peneira para auxiliar neste processo para retirada dos resíduos da polpa que ainda estavam fixados no caroço conforme figura 02.

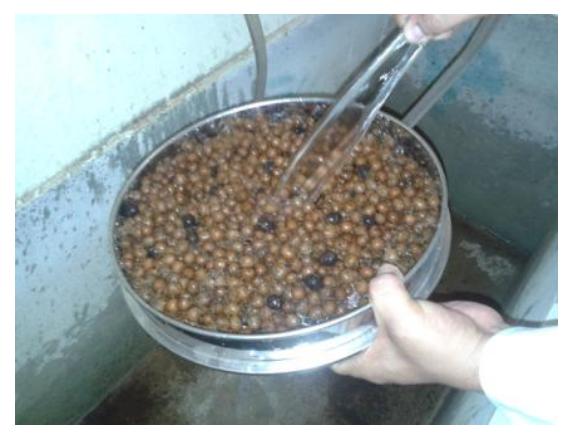

Figura 02: Caroços de açaí no processo de lavagem.

$\mathrm{Na}$ sequência os caroços foram encaminhados para secagem em estufa a $\pm 100^{\circ} \mathrm{C}$ até estabilização da massa seca. Estando secos, os caroços passaram pela operação unitária de moagem em moinhos de martelo, onde também ocorreu a separação da fibra da semente.

Mistura das fibras moídas com a resina poliéster.

A resina foi catalisada conforme recomendação do fabricante (adesivo para laminação Carplast). Este descreve que para cada $100 \mathrm{~g}$ de resina deve-se usar de 20 a 25 gotas do catalisador. Porém, neste trabalho, as gotas de catalisador foram inseridas após a mistura da fibra com a resina, sendo realizada manualmente nas proporções $25 \%$ e $50 \%$ de fibra.

Conformação dos corpos de provas para ensaios de flexão.

Estando a mistura pronta, está foi inserida em um molde de madeira com as paredes revestidas de zinco nas dimensões $30 \times 8 \times 5 \mathrm{~cm}$ para conformação de um corpo de provas (CP) nas dimensões 20x5cm (dimensões descritas na Norma NBR 14810, 2002). 


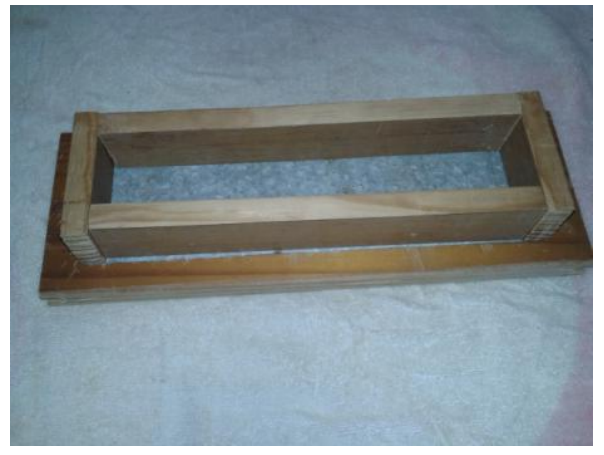

Figura 03: Molde para conformação dos CP's de flexão.

Para cada composição foram conformados 4 CP's conforme figura 04 abaixo.
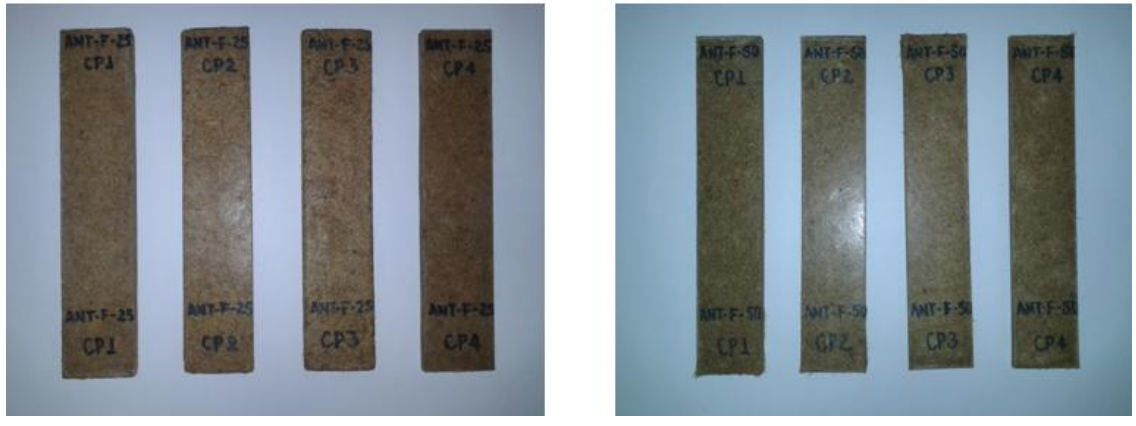

Figura 04: CP's conformados nas proporções de 25\% (a esquerda) e 50\% (a direita) de fibra.

\section{RESULTADOS E DISCUSSÃO}

Os CP's desenvolvidos apresentaram os resultados para os ensaios de resistência a flexão conforme tabela 01 .

Tabela 01 - Composições e resultados dos ensaios de para resistência a flexão

\begin{tabular}{|r|c|}
\hline Composição & Média de resistência (Mpa) \\
\hline \hline $0 \%$ de fibra & 48,83 \\
\hline \hline $25 \%$ de fibra & 26,77 \\
\hline $50 \%$ de fibra & 25,78 \\
\hline
\end{tabular}




\section{9 a 22 de outubro de 2014 \\ Florianópolis/SC}

Os resultados mostram que os CP's onde há apenas a resina poliéster apresentaram elevada resistência quando comparados com os CP's que tem em suas composições a fibra do caroço do açaí. Observa-se também que mesmo com o aumentando do percentual de fibra de $25 \%$ para $50 \%$ de fibra houve uma pequena diferença na resistência, mostrando assim, uma certa estabilidade.

\section{CONCLUSÃO}

Os compósitos reforçados com fibras apresentam propriedades mecânicas avantajadas como maior limite de resistência, o compósito em estudo (neste caso a fibra do caroço do açaí com resina) pode ser utilizado na obtenção de móveis e divisórias em geral, umas vez que este compósito apresentou alta resistência a flexão.

Com isso, observando a quantidade de resíduos gerados do açaí gerados no Amapá, tendência do uso de fibras vegetais em matriz polimérica e os resultados obtidos nos testes de flexão nota-se o quanto é viável a aplicação da fibra do açaí na produção de compósito.

\section{REFERENCIAS}

ASKEland, D. R.; PHulÉ, P. P. Ciência e Engenharia dos Materiais. Ed. Cengage Learning, p. 594, São Paulo: 2008.

Associação Brasileira de Normas Técnicas, Norma NBR 14810 - 1, Chapas de madeira aglomerada - Terminologia. Rio de Janeiro: 2002.

CALLISTER JR, W. D. Ciência e Engenharia de Materiais: Uma introdução. Ed. LTC, 7oed, 692 p. Rio de janeiro: 2008.

IBGE. Produção da Extração Vegetal e da Silvicultura, 2006. Disponível em: http://www.ibge.gov.br/home/presidencia/noticias/noticia_visualiza.php?id_noticia=1052>.

Acesso em : junho de 2013.

MARINHO, J.R. D. Macromoléculas e Polímeros. Barueri - SP, Ed. Manole, 2005.

RODRÍGUEZ-ZÚÑIGA, U. F; FARINAS, C. S.; BERTUCCI NETO, V. ; LEMO, V.Produção de Complexos Lignoceluliticos em Substratos Derivados de Resíduos Agroindustriais por Fermentação Semi-sólida. In: WORKSHOP DE BIOCATÁLISE E BIOTRANSFORMAÇÃO, 4., 2008, São Carlos. Livro de resumos... São Carlos, SP: Instituto de Química de São Carlos, 2008. p. 107. resumo expandido. Anais.

SABARIZ, A.; SILVA, V. R. V.; SILVA, L. J.; MARQUES, D. Propriedades mecânicas de compósitos formados por matriz epóxidica reforçada com fibras vegetais. $17^{\circ} \mathrm{CBECIMat,} 11$ p., Foz do Iguaçu, PR, Brasil, 2006. 